\title{
Five year evaluation of the complications observed in porcelain fused to metal (PFM) crowns placed at a university hospital
}

Shizrah Jamal

Aga Khan University, shizrah.jamal@aku.edu

Rabia Ghafoor

Aga Khan University, robia.ghafoor@aku.edu

Farhan Raza Khan

Aga Khan University, farhan.raza@aku.edu

Kamil Zafar

Aga Khan University, kamil.zafar@aku.edu

Follow this and additional works at: https://ecommons.aku.edu/

pakistan_fhs_mc_surg_dent_oral_maxillofac

Part of the Dentistry Commons, and the Surgery Commons

\section{Recommended Citation}

Jamal, S., Ghafoor, R., Khan, F. R., Zafar, K. (2020). Five year evaluation of the complications observed in porcelain fused to metal (PFM) crowns placed at a university hospital. JPMA. The Journal of the Pakistan Medical Association, 70(5), 845-850.

Available at: https://ecommons.aku.edu/pakistan_fhs_mc_surg_dent_oral_maxillofac/149 


\title{
Five year evaluation of the complications observed in porcelain fused to metal (PFM) crowns placed at a university hospital
}

Shizrah Jamal, Robia Ghafoor, Farhan Raza Khan, Kamil Zafar

\begin{abstract}
Objective: To determine the frequency of complications in crowns cemented over a 5-year period in a tertiary care hospital and also to report the survival of these crowns.

Methods: The retrospective cross-sectional study was conducted at the Aga Khan University Hospital, Karachi, from March 2017 to March 2018 and comprised porcelain-fused-to-metal crowns placed on the anterior or posterior teeth that were fabricated at the institutional laboratory and were placed in institutional dental clinics in the preceding 5 years. Porcelain-fused-to-metal The crowns were clinically and radio-graphically evaluated in a duration of two months for presence / absence of complications. Factors associated with the failure of the crowns, their survival and the impact of covariates, like gender, flossing and bruxism, on the survival time were determined. Data was analysed using SPSS 22.

Results: There were 150 crowns related to 107 patients who had a mean age of $45.0 \pm 11.4$ years. The most common complication observed was open proximal contacts $9(6 \%)$ followed by de-cementation $8(5.3 \%)$, porcelain chipping $9(6 \%)$ and abutment fracture $2(1.3 \%)$. The 5 -year survival rate of the crowns was $127(84.7 \%)$. The mean follow-up time was $57.2 \pm 1.0$ months. Overall, year-wise survival of PFM crowns for one year till five years was 147 (98\%), 144 (96\%), 135 (90\%), 130 (86\%) and 119 (79\%) respectively.
\end{abstract}

Conclusion: The porcelain-fused-to-metal crowns had a high 5-year survival rate. Open proximal contacts represented the most common complication.

Keywords: Complications, Crown, Metal-ceramic. (JPMA 70: 845; 2020).

https://doi.org/10.5455/JPMA.16442

\section{Introduction}

Dental crown is an indirect full cuspal coverage restoration that is placed over a prepared tooth. A prepared tooth can be a root treated or any tooth that is structurally compromised. ${ }^{1}$ A crown is indicated when the abutment tooth cannot be restored to full form, function or desired aesthetics with any other conservative means. There are three broad categories of crowns; all metal, all ceramic, or metal-ceramic which is also known as porcelain-fused-to-metal (PFM) crown. ${ }^{2}$ In a PFM crown, the core consists of a nickel / cobalt / chromium alloy that is overlaid by dental glass porcelain. ${ }^{2}$ The cast metal provides the desired strength, whereas porcelain offers the optimum aesthetics by matching with the form of the adjacent teeth. PFM crowns are affixed to the tooth

Department of Surgery, Aga Khan University Hospital, Karachi, Pakistan. Correspondence: Shizrah Jamal. e-mail: shiz.jamal@gmail.com structure using adhesive cement; most commonly, a glass-ionomer-based cement. ${ }^{2}$ Compared to other types of crowns, the PFM crowns have properties of high strength, aesthetic appearance and relative cost effectiveness. For these reasons, PFM restorations are considered one of the standard indirect full cuspal coverage restorations. 2,3

Various complications are observed in the PFM crowns. These include chipped-off ceramic, recurrent caries and / or loss of retention.4,5 Multiple factors are responsible for or are associated with these complications. These are broadly categorised as patient-related, operator-related and technician-related factors. Patient-related factors are para-function (clenching and bruxism), traumatic biting habits (biting on ice cubes, betel nuts etc.) and heavy occlusal forces. Operator-related problems include poor treatment planning, inadequate preparation of 
tooth, improper impression-making, and poor adaptation of the crown, inadequate cementation and failure to attain correct occlusion at crown placement. 5 Technicianrelated errors are improper pattern making, suboptimal casting of metal core leading to marginal gaps, improper layering of porcelain, inappropriate firing of porcelain or incorrect surface finish leading to excessive plaque retention. 6

Multiple studies have reported about the survival of PFM crowns, $^{5-7}$ such as $94 \%$ after 10 years. $55.5 \%$ over three years, ${ }^{8}$ and $85 \%$ after five years. ${ }^{9}$ Hence, considerable variability exists regarding the survival of PFM crowns.

Chipped-off porcelain is the most frequently observed complication in PFM crowns. ${ }^{10}$ Ozer et al. reported that the frequency of porcelain chipping is $5.7 \%$ over the period of 5 years.7 Frequency of complications reported by Walton et al. was $1.03 \%$ in five years. ${ }^{5}$ Recurrent caries is another problem; its prevalence among crowned teeth varied between $0.06 \%$ and $1.3 \%$ in 5 years of prosthesis placement. ${ }^{11}$

Complications reported in the literature according to location of the teeth are also variable. Behr et al. concluded that there was no significant difference regarding frequency of porcelain chipping in PFM crowns in anterior or posterior teeth. ${ }^{11}$ However, another study ${ }^{12}$ reported more porcelain chipping off among the anterior teeth compared to the posterior teeth.

Studies carried out in Pakistani population have reported biological and technical complications in PFM crowns with a mean survival of 4.5 years. ${ }^{13,14}$ However, the data included cases done not only by the qualified dentists but the non-qualified clinicians (quacks) as well. Moreover, those crowns were fabricated by various known and unknown laboratories and technicians' skills were also variable. Therefore, the results cannot be generalised. The cross-sectional study design of the locally reported studies and the assessment of prosthesis done by various practitioners have made the study results questionable as it remains unknown whether those complications were present at the time of crown placement or were developed later.

The current study was planned to evaluate the frequency of complications observed in PFM crowns and to identify the factors that may predict the longevity of the PFM crowns.

Vol. 70, No. 5, May 2020

\section{Materials and Methods}

The retrospective cross-sectional study was conducted at the Aga Khan University Hospital (AKUH), Karachi, from March 2017 to March 2018 and comprised PFM crowns placed on the anterior or posterior teeth that were fabricated at the AKUH laboratory and were placed in the AKUH dental clinics in the preceding 5 years. Nonprobability convenience sampling was used to raise the sample. After approval was obtained from the institutional ethics review committee, the sample size was calculated using World Health Organisation (WHO) calculator 15 while using keeping the 5 -year event-free survival rate of PFM crowns as $92 \%{ }^{11}$ and keeping an absolute precision of $5 \%$ and confidence level of $95 \%$. Patients with incomplete records and all-ceramic crowns or all-metal crowns were excluded. Informed consent, as a matter of institutional policy, is taken from all patients who visit the hospital for using clinical data for research, scholarly activities.

The parameters of interest were complications, such as record of recurrent caries, development of open proximal contact, de-cementation, abutment fracture and porcelain chipping which was defined as partial or complete loss of porcelain from the alloy substrate. The record of recurrent caries was verified on bitewing radiograph and was considered a failure when the defects were so severe that the abutment tooth was in danger or already fractured, and in such cases, a new crown was made. Crowns that got decemented due to dissolution of the luting agent were also considered failed. For the purpose of the study, one proximal contact i.e. absence of tight proximal contact or open proximal contact, was labelled as failure.

Crowns that were intact in terms of sealed margins, exhibited suitable occlusal morphology and served the intended function were considered success. Whereas crowns that exhibited recurrent decay or underwent dislodgement due to decementation or abutment fracture or underwent porcelain chipping off were considered failure. Since mere retention of crown does not necessarily mean success, therefore the presence of an open proximal contact where other parameters of success were met, were labelled as survival only.

For the evaluation of the technical performance of crowns, United States Public Health Service (USPHS) criteria ${ }^{16}$ were employed. An outcome was rated Alfa $(A)$, when no problem occurred; Bravo (B), when small 
but clinically acceptable defects were found; Charlie (C), when the defects reached a level no longer clinically acceptable; and Delta (D), when the prosthesis had to be replaced due to the defect. All patients were informed about the clinical status of their crown(s). For the study, the crowns rated A or B were considered success, $C$ as survival only when it was clinically and radio-graphically confirmed by the single trained dentist, and $D$ as failure.

SPSS version 22 was used for data analysis. Mean and standard deviation (SD) of the continuous variables were computed. Frequencies and percentages of complications of categorical variables, such as recurrent caries, status of proximal contact, decementation, fracture of abutment and porcelain chipping off was determined. Odds ratio (OR) was used to identify factors associated with PFM crowns failure. Survival of PFM crowns was determined using inverse Kaplan-Meier analysis. Cox proportional hazards model was used to determine the impact of covariates, like gender, flossing and bruxism, on the survival time of PFM crowns. Level of significance was kept at $<0.05$.

\section{Results}

There were 150 crown related to 107 patients who had a mean age of $45.0 \pm 11.4$ years. There were $34(32 \%)$ males

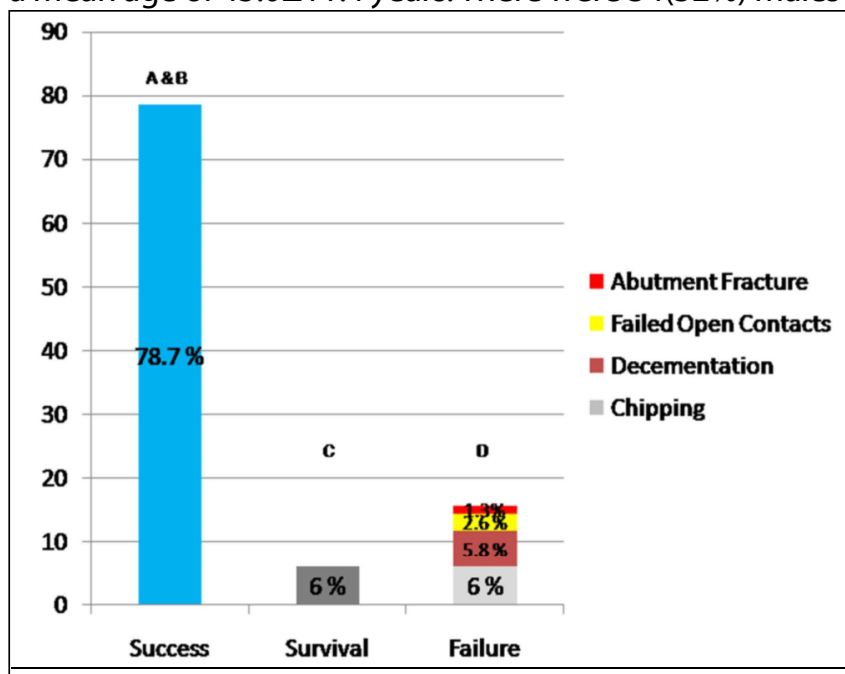

Figure-1: Success, Survival \& Failure of the porcelain-fused-to-metal (PFM) crowns observed using United States Public Health Service (USPHS) criteria $(n=150)$. Alpha (A) when no problem occurred Bravo (B) when small but clinically acceptable were collectively considered as successful crowns. Charlie (C) when the defects reached a level no longer clinically acceptable. This category comprises of open proximal contacts. Delta (D) when the crown had to be replaced due to the defect, including porcelain chipped off, de-cementation, recurrent decay and abutment fracture and open proximal contacts with symptoms. and $73(68 \%)$ females, and 54(50.5\%) of the total subjects were aged $30-50$ years (Table 1 ). Of all the patients,

Table-1: Characteristics of the patients $(n=107)$ who received 150 crowns.

\begin{tabular}{lc}
\hline Variable & $\mathbf{n}(\%)$ \\
\hline Patient level data (n=107) & \\
Age (years) & \\
$<30$ & $17(15.9)$ \\
$30-50$ & $54(50.5)$ \\
$>50$ & $36(33.6)$ \\
Gender & \\
Male & $34(31.8)$ \\
Female & $73(68.2)$ \\
Brushing & \\
Once daily & $58(54.2)$ \\
Twice daily & $49(45.8)$ \\
Flossing & \\
No & $48(44.9)$ \\
1-2 per week & $30(28.0)$ \\
Daily & $29(27.1)$ \\
Tooth wear & \\
Yes & $2(1.9)$ \\
No & $105(98.1)$ \\
Betel nut habits & \\
Yes & $2(1.9)$ \\
No & $105(98.1)$ \\
Crown level data (n=150) & \\
Location of crown & \\
Maxillary & \\
Mandibular & \\
Opposing dentition & $77(51.3)$ \\
Present or absent & $73(48.6)$ \\
Natural were artificial & \\
Number of crowns per subject & $10(6.7)$ \\
One crown & $140(93.3)$ \\
2 or more crowns & \\
\hline & $80(53.3)$ \\
\hline & $70(46.6)$ \\
\hline
\end{tabular}

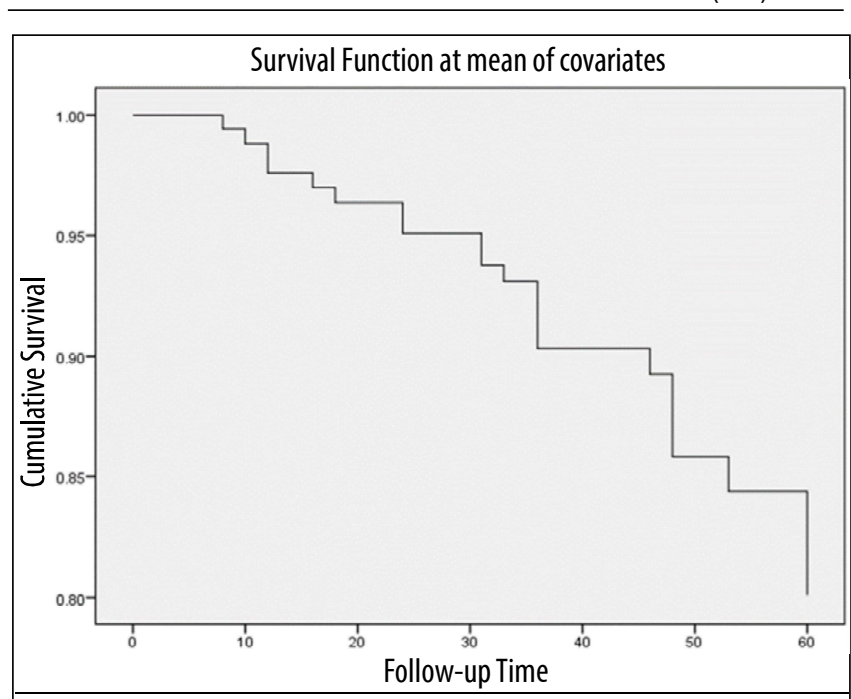

Figure-2: Cumulative survival of PFM crowns in five years using Cox proportional hazard's analysis $(n=150)$. 
Table-2: Factors associated with the failure of porcelain-fused-to-metal (PFM) crowns.

\begin{tabular}{|c|c|c|c|c|}
\hline Variables & $\begin{array}{c}\text { Categories } \\
\text { (Failures) } \\
(n=23)\end{array}$ & $\begin{array}{c}\text { Complications } \\
\text { (successful \& surviva } \\
(n=127)\end{array}$ & $\begin{array}{l}\text { Unremarkable } \\
\text { al) Odds Ratio }\end{array}$ & $95 \% \mathrm{Cl}$ \\
\hline \multicolumn{5}{|c|}{ Patient level data $(n=107)$} \\
\hline $\begin{array}{l}\text { Gender } \\
\text { Female } \\
\text { Male }\end{array}$ & $\begin{array}{c}18(16.8 \%) \\
5(4.7 \%)\end{array}$ & $\begin{array}{l}45(42.1 \%) \\
39(36.4 \%)\end{array}$ & 3.12 & $1.12-8.17$ \\
\hline $\begin{array}{l}\text { Age in years } \\
\begin{array}{l}30+ \\
<30\end{array}\end{array}$ & $\begin{array}{c}22(20.6 \%) \\
1(0.9 \%)\end{array}$ & $\begin{array}{c}68(63.5 \%) \\
16(15 \%)\end{array}$ & 5.17 & $0.87-56.79$ \\
\hline $\begin{array}{l}\text { Brushing } \\
\text { Once } \\
\text { Twice }\end{array}$ & $\begin{array}{c}15(14.02 \%) \\
8(7.4 \%)\end{array}$ & $\begin{array}{l}43(40.2 \%) \\
41(38.3 \%)\end{array}$ & 1.78 & $0.72-4.67$ \\
\hline $\begin{array}{l}\text { Flossing } \\
\text { No } \\
\text { Yes }\end{array}$ & $\begin{array}{c}15(14.1 \%) \\
8(7.5 \%)\end{array}$ & $\begin{array}{l}33(30.8 \%) \\
51(47.6 \%)\end{array}$ & 2.89 & $1.16-7.62$ \\
\hline \multicolumn{5}{|c|}{ Crown level data $(n=150)$} \\
\hline $\begin{array}{l}\text { Number of .crowns } \\
\text { Single crown } \\
\text { Multiple crown }\end{array}$ & $\begin{array}{l}13(8.7 \%) \\
10(6.6 \%)\end{array}$ & $\begin{array}{c}67(44.7 \%) \\
60(40 \%)\end{array}$ & 1.16 & $0.49-2.90$ \\
\hline $\begin{array}{l}\text { Opposing tooth } \\
\text { Natural } \\
\text { Artificial }\end{array}$ & $\begin{array}{c}22(14.7 \%) \\
1(0.6 \%)\end{array}$ & $\begin{array}{c}116(77.4 \%) \\
11(7.3 \%)\end{array}$ & 2.08 & $0.32-23.46$ \\
\hline $\begin{array}{l}\text { Location of crown } \\
\text { Maxilla } \\
\text { Mandible }\end{array}$ & $\begin{array}{c}12(8 \%) \\
11(7.3 \%)\end{array}$ & $\begin{array}{l}65(43.4 \%) \\
62(41.3 \%)\end{array}$ & 1.04 & $0.44-2.47$ \\
\hline $\begin{array}{l}\text { Bruxism } \\
\text { Yes } \\
\text { No }\end{array}$ & $\begin{array}{l}2(1.4 \%) \\
21(14 \%)\end{array}$ & $\begin{array}{c}1(0.6 \%) \\
126(84 \%)\end{array}$ & 12.0 & $1.31-174.70$ \\
\hline
\end{tabular}

Table-3: Multivariable regression analysis of factors affecting survival of porcelain-fused-to-metal (PFM) crowns.

\begin{tabular}{lcccc}
\hline Variables in the model & B & SE & Wald & p-value \\
\hline Gender & 0.28 & 0.51 & 0.29 & 0.58 \\
Flossing & -0.37 & 0.25 & 2.06 & 0.49 \\
Bruxism & 2.07 & 0.78 & 6.99 & 0.008 \\
\hline
\end{tabular}

Cox proportional hazards model was used. Level of significance was kept at 0.05 .

$2(1.8 \%)$ had bruxism and $2(1.8 \%)$ had a history of betel nut chewing (Table 2 ).

There were $118(78.7 \%)$ cases of success, $23(15.5 \%)$ of failure and $9(6 \%)$ of survival (Figure 1). Factors associated with failure of PFM crown were noted separately (Tables 2-3).

The 5-year survival rate of the PFM crowns was $127(84.7 \%)$, and the mean follow-up time was $57.2 \pm 1.0$ months (Figure 2). Overall, year-wise survival of PFM crowns for one year till five years was 147 (98\%), 144 (96\%), 135 (90\%), 130 (86\%) and 118 (78.7) respectively.

\section{Discussion}

In this five-year follow-up study, 15.3\% PFM crowns failed due to various complications such as open proximal contact, porcelain chipping, decementation, recurrent caries and abutment fractures. Previous studies have reported that open proximal contact may lead to food impaction, papillitis leading to proximal caries and bone loss. 17,18 In this study frequency of open proximal contacts in PFM crowns turned out to be $13(8.7 \%)$ out of which $4(2.6 \%)$ were considered as total failure. Although local studies on crowns complications 16,17 reported on the crowns' success rates and complications, but the current study has not only determined 5-year survival rate, but has also employed regression analysis to identify the factors responsible for crown failures.

proximal contacts in the present study, only four people presented with the complaint of papillitis and food impaction. Change in status of proximal contact from tight to acceptable has also been reported by another study 19 but it did not report any crowns with open contact, whereas, in the present study, it was observed as a major complication. The open proximal contacts can occur due to multiple reasons. One reason could be the mesial or distal drifting of the tooth when the adjacent tooth is absent or over eruption of the tooth has taken place secondary to opposing missing dentition. Missing adjacent or opposing dentition for a considerable period of time may lead to changes in occlusion.20 Another reason could be the periodontal status of dentition. A large number of people in developing countries chew tobacco, areca nut and consume other substances of oral abuse, and do not maintain oral hygiene. This results in poor dental health, excessive gingival recession and stagnation of food in the interdental areas. The frequency of the brushing and flossing reported in this study signifies the change in periodontal apparatus due to negligence in oral hygiene care. The standard of care is to carry out regular follow-ups to evaluate such changes with the passage of time, reinforce oral hygiene maintenance and rectify them timely. Ideally, open proximal contact in a crown should be considered a failure but a subset of such crowns, which tend to function normally, can be monitored regularly as a cost- 
effective approach and should be changed when signs of clinical complications are noticed.

Porcelain chipping of the PFM crowns is a frequently reported complication in studies.9-11 In the present study, such an event occurred in $9(6 \%)$ of all the cases. Walton et al. ${ }^{5}$ reported that metal-ceramic crowns also showed a relatively short period of service at 6.5 years, needing replacement primarily because of porcelain failure. The frequency of porcelain chipping off reported in literature ranges from $1.7 \%$ to $17 \%$ depending on which setup a study has been carried out. Multi-centre data or records from teaching institutions report higher frequencies. Kinsel et al. ${ }^{21}$ reported a seven-time higher risk of porcelain fractures for patients with bruxism. The same high OR was calculated in our study for patients with bruxism facing more complications in PFM crowns. In this study, association was noted between failures and betel nut chewing habit, but this might have been due to the low number of patients presenting with the habit of betel nut chewing or because of under-reporting of the habits by the patients. No significant association was found with the type of antagonist and failures of PFM crowns which is in agreement with earlier results. ${ }^{11}$

The subjects in this study showed loss of retention or decementation to be around $6 \%$. It is a multi-factorial complication which depends on the habits of the patient, taper and height of crown preparation or the type of cement used. As all the crowns that were evaluated in the study were luted with glass-ionomer cement, so this could not be a factor influencing the loss of retention in our study. In this study fewer patients with bruxism were evaluated, yet statistical analysis showed high odds, suggesting that this factor cannot be entirely excluded. The taper and height of the crown may vary from one tooth to another due to the remaining coronal structure as well as on clinician's expertise. This might be the most probable factor affecting the outcome in the study conducted in a teaching institution like ours. The results of this study were in accordance with Behr et al. ${ }^{11}$ who identified loss of retention to be the second most common complication for single crowns. Other authors found comparable low rates of these complications. 9,10

The present study did not find any recurrent caries around PFM crowns. This could be an under-estimation of the cases due to metal coping, which can obscure the examination clinically as well radio-graphically. The frequency of failures reported due to recurrent caries turned out to be low in this study, but it is in agreement with other studies. ${ }^{9-11}$ The cases with abutments fracture were just above $1 \%$. The number of events was too low for a sufficient statistical analysis.

Success of a dental restoration is determined by the problem-free service life it offers. Mere absence of complications does not mean success. ${ }^{22}$ The mere presence of a crown in functional state can misclassify the actual success of the crown. It has been stated that crown remaining in the oral cavity in spite of having complications over-estimates the survival of crowns.22 The overall survival of PFM crowns in this study was $84 \%$ over a period of 4.5 years; these are lower than the results reported earlier.9,10

The present study has some limitations, like its retrospective design. In addition, there were very few patients in the sample with bruxism and betel nut chewing habits.

Multi-centre, prospective studies are needed to study the failure of PFM crowns. Patients with bruxism and subjects with the habit of betel nut chewing should be considered at a higher risk of crown failure. Attention should be given to proximal contacts and contours in the PFM crowns to avoid open proximal contacts.

\section{Conclusion}

PFM crowns fabricated and placed in our hospital were found to have acceptable survival rates.

Disclaimer: None.

Conflict of Interests: None.

Source of Funding: None.

\section{References}

1. Tikku AP, Chandra A, Bharti R. Are full cast crowns mandatory after endodontic treatment in posterior teeth? J Conserv Dent 2010; 13: 246-8.

2. Anusavice KJ, Kakar K, Ferree N. Which mechanical and physical testing methods are relevant for predicting the clinical performance of ceramic-based dental prostheses? Clin Oral Implants Res 2007; 18 Suppl 3: 218-31.

3. Levi L, Barak S, Katz J. Allergic reactions associated with metal alloys in porcelain-fused-to-metal fixed prosthodontic devices-A systematic review. Quintessence Int 2012; 43: 871-7.

4. Reitemeier B, Hansel K, Kastner C, Walter MH. Metal-ceramic failure in noble metal crowns: 7-year results of a prospective clinical trial in private practices. Int J Prosthodont 2006; 19: 397-9.

5. Walton TR. Changes in the outcome of metal-ceramic toothsupported single crowns and FDPs following the introduction of osseointegrated implant dentistry into a prosthodontic practice. Int J Prosthodont 2009; 22: 260-7. 
6. Singh D, Nishad SG, Sharma M, Sareen A. Marginal integrity of metal copings of various porcelain fused to metal alloys using different ring casting techniques: A systematic literature review. Eur J Prosthodont 2014; 2: 7

7. Ozer F, Mante FK, Chiche G, Saleh N, Takeichi T, Blatz MB. A retrospective survey on long-term survival of posterior zirconia and porcelain-fused-to-metal crowns in private practice. Quintessence Int 2014; 45: 31-8.

8. Pjetursson BE, Sailer I, Zwahlen M, Hammerle $\mathrm{CH}$. A systematic review of the survival and complication rates of all-ceramic and metal-ceramic reconstructions after an observation period of at least 3 years. Part I: Single crowns. Clin Oral Implants Res 2007; 18 Suppl 3: 73-85.

9. Rinke S, Kramer K, Burgers R, Roediger M. A practice-based clinical evaluation of the survival and success of metal-ceramic and zirconia molar crowns: 5-year results. J Oral Rehabil 2016; 43: 136-44.

10. Shi JY, Li X, Ni J, Zhu ZY. Clinical Evaluation and Patient Satisfaction of Single Zirconia-Based and High-Noble Alloy Porcelain-Fusedto-Metal Crowns in the Esthetic Area: A Retrospective Cohort Study. J Prosthodont 2016; 25: 526-30.

11. Behr M, Zeman F, Baitinger T, Galler J, Koller M, Handel G, et al. The clinical performance of porcelain-fused-to-metal precious alloy single crowns: chipping, recurrent caries, periodontitis, and loss of retention. Int J Prosthodont 2014; 27: 153-60.

12. Ozcan $M$, Niedermeier $W$. Clinical study on the reasons for and location of failures of metal-ceramic restorations and survival of repairs. Int J Prosthodont 2002; 15: 299-302.

13. Saleem T, Amjad F, Bhatti MUD. Complications associated with tooth supported fixed dental prosthesis amongst patients visiting university college of dentistry Lahore. Pak Oral Dent J 2013; 33; 207-11.
14. Raza M, Fahimullah, Fayyaz M, Akram S. Complications and their severity in patients of conventional metal ceramic fixed dental prosthesis: A clinical study. Pak Oral Dent J 2015; 35: 155-8.

15. Lwanga SK, Lemeshow S. Sample size determination in health studies: a practical manual. Geneva: World Health Organization; 1991.

16. Vigolo P, Mutinelli S. Evaluation of zirconium-oxide-based ceramic single-unit posterior fixed dental prostheses (FDPs) generated with two CAD/CAM systems compared to porcelain-fused-to-metal single-unit posterior FDPs: a 5-year clinical prospective study. J Prosthodont 2012; 21: 265-9.

17. Durr ES, Ahmad Z. Porcelain fused to metal (PFM) crowns and caries in adjacent teeth. J Coll Physicians Surg Pak 2011; 21: 134-7.

18. Koral SM, Howell TH, Jeffcoat MK. Alveolar bone loss due to open interproximal contacts in periodontal disease. J Periodontol 1981; 52: 447-50.

19. Bindl A, Mormann WH. Survival rate of mono-ceramic and ceramiccore CAD/CAM-generated anterior crowns over 2-5 years. Eur J Oral Sci 2004; 112: 197-204.

20. Craddock HL, Youngson CC, Manogue M, Blance A. Occlusal changes following posterior tooth loss in adults. Part 2. Clinical parameters associated with movement of teeth adjacent to the site of posterior tooth loss. J Prosthodont 2007; 16: 495-501.

21. Kinsel RP, Lin D. Retrospective analysis of porcelain failures of metal ceramic crowns and fixed partial dentures supported by 729 implants in 152 patients: patient-specific and implant-specific predictors of ceramic failure. J Prosthet Dent 2009; 101: 388-94.

22. Scurria MS, Bader JD, Shugars DA. Meta-analysis of fixed partial denture survival: prostheses and abutments. J Prosthet Dent 1998; 79: 459-64. 